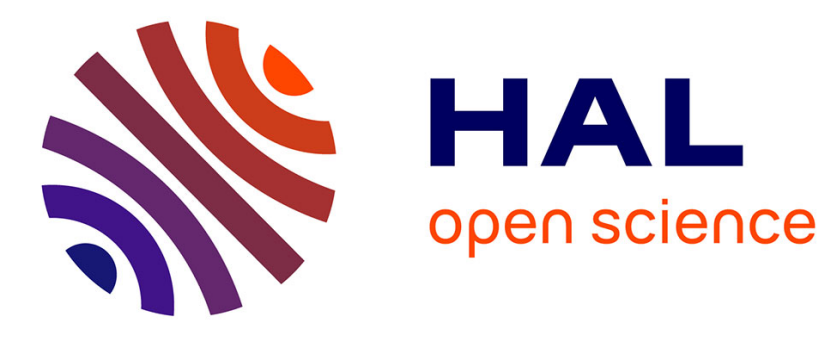

\title{
Dynamics of a Lean Flame Stabilized by Nanosecond Discharges
}

Victorien Blanchard, Nicolas Minesi, Sergey Stepanyan, Gabi Daniel Stancu, Christophe O Laux

\section{- To cite this version:}

Victorien Blanchard, Nicolas Minesi, Sergey Stepanyan, Gabi Daniel Stancu, Christophe O Laux. Dynamics of a Lean Flame Stabilized by Nanosecond Discharges. AIAA Scitech 2021 Forum (Session: Plasma-Assisted Combustion II), Jan 2021, VIRTUAL EVENT, United States. 10.2514/6.2021-1700 . hal-03117130

\author{
HAL Id: hal-03117130 \\ https://hal.science/hal-03117130
}

Submitted on 20 Jan 2021

HAL is a multi-disciplinary open access archive for the deposit and dissemination of scientific research documents, whether they are published or not. The documents may come from teaching and research institutions in France or abroad, or from public or private research centers.
L'archive ouverte pluridisciplinaire HAL, est destinée au dépôt et à la diffusion de documents scientifiques de niveau recherche, publiés ou non, émanant des établissements d'enseignement et de recherche français ou étrangers, des laboratoires publics ou privés. 


\title{
Dynamics of a lean flame stabilized by nanosecond discharges
}

\author{
Victorien P. Blanchard ${ }^{1}$, Nicolas Q. Minesi², Sergey Stepanyan ${ }^{3}$, Gabi- \\ Daniel Stancu ${ }^{4}$, and Christophe O. Laux ${ }^{5}$ \\ Laboratoire EM2C, CNRS, CentraleSupélec, Université Paris-Saclay, 91190 Gif-sur-Yvette
}

\begin{abstract}
Non-equilibrium plasmas are known to improve ignition and extend flammability limits. In this study, NRP discharges of $2 \mathrm{~mJ}$ are applied at $20 \mathrm{kHz}$ in the recirculation zone of a premixed methane-air bluff-body burner with a lean equivalence ratio of 0.8 . The operating point is close to the lean blow out limit and NRP discharges efficiently enhance the combustion process. Discharge effects are investigated and the role of $\mathrm{N}_{2}(\mathrm{C})$ is quantified with spectroscopic measurements.
\end{abstract}

\section{Introduction}

To meet the requirements of sustainable development, it is crucial to improve energy systems. Efficiency increase and pollutant emissions reduction set out guidelines for design. In many fields, especially transport and industry, there is no appropriate alternative to combustion-based energy production. Noticeable improvement relies mainly on burning regimes beyond current limits, such as lean combustion for gas turbine engines [1] or with a high degree of exhaust gas recirculation for automotive engines [2],[3]. Plasmas have demonstrated their ability to extend the operability of many combustion systems. Plasma effects on combustion gas mixture are carefully studied for many years. Several works have shown a significant lean blow out limit extension using Nanosecond Repetitively Pulsed (NRP) discharges in premixed flames [4]-[7] for different fuels [8]. The ignition probability is higher and the performances are better than with conventional spark discharges [9], [10]. Control of thermoacoustic instabilities [11], [12] and reduction of Nitrogen Oxides (NOx) [13] are also obtained using NRP and microwave discharges. Three combustion-enhancement effects have been evidenced: thermal, kinetic and hydrodynamic. They are generally coupled, making their relative contributions challenging to investigate and model. Numerical simulations are necessary to design plasma-assisted combustion systems. However, the lack of affordable models is currently a real constraint.

NRP discharges have been thoroughly studied both experimentally and numerically [14]-[18]. During the pulse duration, these non-equilibrium discharges efficiently generate high electron number densities at a low power budget. Electron-impact reactions then produce excited species and radicals. In preheated air at $1000 \mathrm{~K}$, these effects are well understood: experimental [17] and numerical [18] studies have proven the existence of ultra-fast heating of about 1000 $\mathrm{K}$ in $20 \mathrm{~ns}$. Nitrogen excited states produced by electron impact are quenched by molecular oxygen, which results in the production of atomic oxygen and heat release. These highly reactive oxygen radicals and heat then enhance combustion. This 2-step mechanism describing $\mathrm{O}_{2}$ dissociation and heat release was implemented and coupled to a high-fidelity combustion DNS solver. Good agreement was obtained with schlieren experimental results focused on the discharge kernel in a methane-air mixture [19]. To extend the validity of this model to complex flame simulations, Bechane et al. recently implemented the model in a high-fidelity combustion LES solver [20], [21]. These numerical results must now be validated against experiments. Further investigations are also required to characterize and model NRP discharge effects in flames. In this work, we seek to characterize the development of a lean flame stabilized by nanosecond discharges to develop and validate a numerical model suitable for high-fidelity plasma-assisted combustion simulations.

\footnotetext{
${ }^{1} \mathrm{Ph}$. D. candidate, Laboratoire EM2C, CNRS, CentraleSupélec, Université Paris Saclay, AIAA Member

${ }^{2} \mathrm{Ph}$. D. candidate, Laboratoire EM2C, CNRS, CentraleSupélec, Université Paris Saclay, AIAA Member

${ }^{3}$ Postdoctoral researcher, Laboratoire EM2C, CNRS, CentraleSupélec, Université Paris Saclay

${ }^{4}$ Professor, Laboratoire EM2C, CNRS, CentraleSupélec, Université Paris Saclay

${ }^{5}$ Professor, Laboratoire EM2C, CNRS, CentraleSupélec, Université Paris Saclay, AIAA Fellow
} 


\section{Experimental Setup}

\section{A. Bluff-body premixed burner: Mini-PAC}

A bluff-body axisymmetric burner, shown in Fig. 1, was chosen to conduct these experiments. Fresh premixed reactants flow into the annular ceramic duct and the concentric stainless-steel bluff-body acts as a flame-holder. The 200-mm-length duct has an inner diameter of $16 \mathrm{~mm}$ and the bluff-body diameter is $10 \mathrm{~mm}$. Nanosecond discharges are produced downstream of the bluff-body between a horizontal tungsten anode of 1-mm diameter centered $5 \mathrm{~mm}$ above the grounded cathode which consists of a 2-mm-height, 1-mm-diameter pin inserted in the middle of the bluffbody. The electrode setup is shown in the inset of Fig. 1.

In this work, the burner operates in a lean combustion regime with an equivalence ratio $\phi=0.8$ at atmospheric pressure. Air and methane flow rates are controlled with two mass flow meters (Bronkhorst High-Tech EL-Flow) set respectively to $\dot{Q}_{a i r}=16 \mathrm{Nm}^{3} \cdot \mathrm{h}^{-1}$ and $\dot{Q}_{\mathrm{CH}_{4}}=1.34 \mathrm{Nm}^{3} \cdot \mathrm{h}^{-1}$. Reactants are premixed in a chamber not represented in Fig. 1 and then injected at the burner's bottom. The theoretical flame thermal power is $\mathrm{P}_{\mathrm{th}}=13.3 \mathrm{~kW}$ and the bulk velocity is $v_{\text {bulk }}=43.3 \mathrm{~m} . \mathrm{s}^{-1}$. The Reynolds number based on the annulus hydraulic diameter is then $\operatorname{Re}=1.6 \times 10^{4}$ which means that the flow is already turbulent upstream of the outlet of the burner.

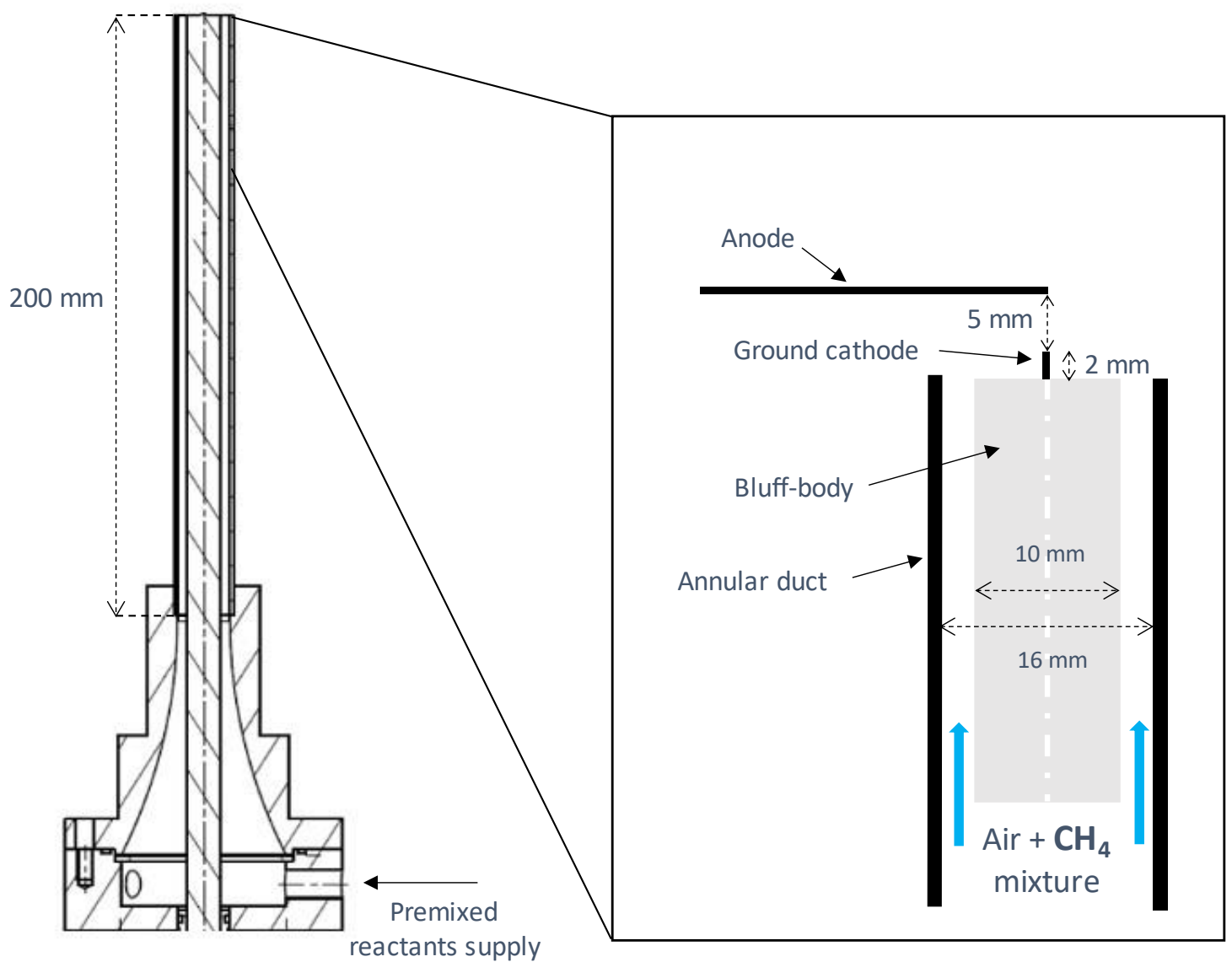

Fig. 1 Schematic view of the Mini-PAC bluff-body burner 


\section{B. High voltage pulse generation and electrical measurements}

Nanosecond discharges are applied at a $20-\mathrm{kHz}$ repetition frequency. Each discharge is produced by a 10 -ns-duration pulse delivered by a high voltage pulse generator (FID Technology model FPG 10-30NM10). A voltage probe (Lecroy PPE 20kV) and a current probe (Pearson current monitor model 6585) are connected to an oscilloscope (Lecroy HDO 6104) to monitor the energy deposited by the discharge. The voltage amplitude of the incident pulse is set so as to obtain $2 \mathrm{~mJ}$ of energy deposited per discharge. The plasma impedance is not equal to the transmission line impedance, hence the incident pulse is partially reflected at the electrode's boundary. Probes are located midway on the cable connecting the pulse generator to the electrode. This configuration allows to separate the incident and reflected pulses. The difference between the incident and reflected pulses is then the energy deposited in the discharge. Voltage, current, and energy traces are plotted in Fig. 2. The energy deposited by the incident pulse is approximately $1.6 \mathrm{~mJ}$ and the remaining energy is deposited by multiple low-energy reflections. The ratio of electric power over flame thermal power is about $0.3 \%$.

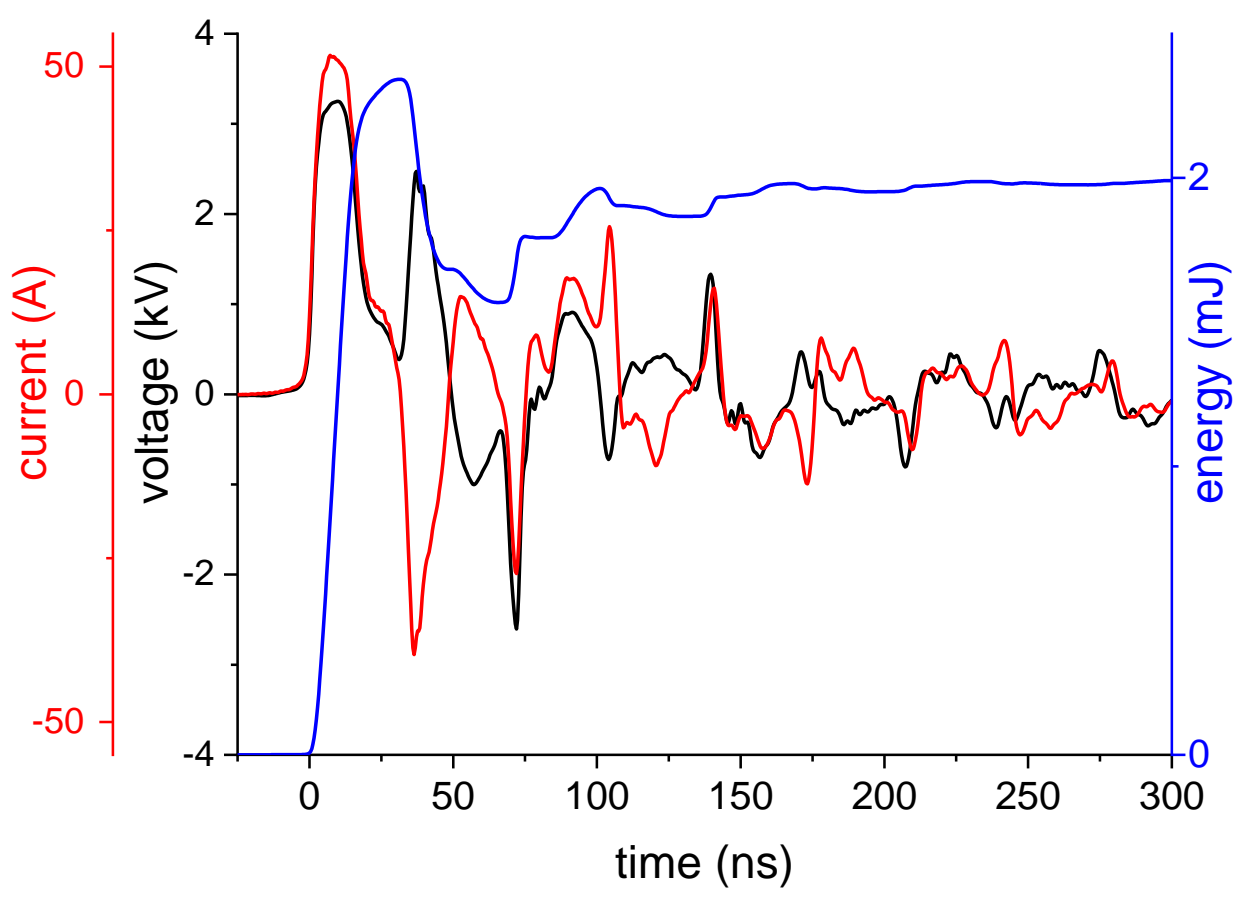

Fig. 2 Voltage (black line), current (red line) and energy (blue line) measurements

\section{Imaging and Optical Emission Spectroscopy}

The discharge emission is characterized using a monochromator (ActonSpectra 2500i) fitted with an ICCD camera (Princeton Instruments PIMAX). The light is collected and focused on the entrance slit with two spherical lenses of 100-mm focal distance. A longpass interference filter with a cutoff wavelength at $300 \mathrm{~nm}$ (UV Melles Griot 03 FCG 121 WG 305) is inserted into the optical path to avoid second-order emission of species emitting in the UV. Spectra are acquired with a 1200 gr.mm $\mathrm{mm}^{-1}$ grating blazed at $300 \mathrm{~nm}$. The spectral resolution is $\Delta \lambda=0.074 \mathrm{~nm}$. Each spectrum is integrated over $2 \mathrm{~ns}$ and calibrated using an integrating sphere (Gooch \& Housego OL 455-4-2) traceable to NIST standards. Discharge and spectra acquisitions are synchronized using a pulse delay generator (BNC Model 575). The complete experimental setup is represented in Fig. 3.

In this work, the number density and rotational temperature of $\mathrm{N}_{2}(\mathrm{C})$ are determined by fitting experimental spectra of the second positive system $\mathrm{N}_{2}$ with SPECAIR [22]. Discharge images are recorded with the monochromator slit 
fully open and aligned with the discharge axis. The grating is placed in $0^{\text {th }}$ order position. During this acquisition, the longpass filter is removed. The discharge diameter is defined as the full width at half-maximum. For the Specair fit, we assumed a homogeneous $\mathrm{N}_{2}(\mathrm{C})$ number density and temperature over a distance equal to the discharge diameter.

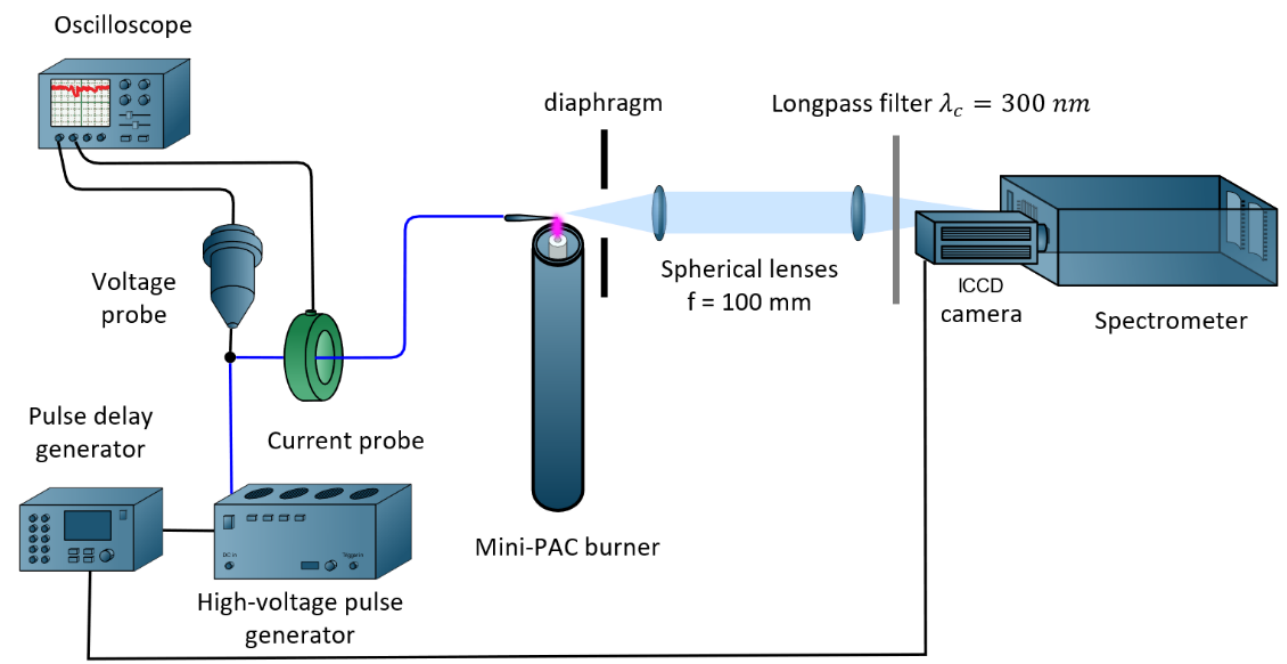

III. Discharge effects on the weak flame

Fig. 3 Schematic diagram of the experimental setup

\section{A. Discharge position}

In air, the primary reactions responsible for heat and atomic oxygen production are [17], [18], [23]:

$$
\begin{aligned}
N_{2}+e^{-} & \rightarrow N_{2}\left(A, B, C, a^{\prime}\right) \\
N_{2}\left(A, B, C, a^{\prime}\right)+O_{2} & \rightarrow N_{2}(v)+2 O\left({ }^{3} P^{1}, D\right)+\Delta T
\end{aligned}
$$

In flames, the gas composition is different, but in the conditions of the present study (premixed methane-air flame, $\phi=0.8), \mathrm{N}_{2}$ is still the major species with a molar fraction above $72 \%$. It is reasonable to consider that the electron energy is mainly transferred to $\mathrm{N}_{2}$ [24] and then, reaction (R1) is sufficient to represent electron-impact reactions. Nevertheless, the quenching of $\mathrm{N}_{2}$ excited states requires specific attention.

Many experimental and numerical studies focus on plasma-assisted ignition, where the discharge is often located in a mixture of hydrogen/oxidizer or hydrocarbon/oxidizer at ambient temperature. In flame stabilization, the discharge is usually located close or upstream of the injection system. Optimal discharge placement was studied by Kim et al. [25], but the conclusions of this study performed in a non-premixed configuration are not relevant for the present work which is conducted with a premixed flame. In recent work with liquid fuels, Vignat et al. [8] showed that the electrode position has a significant impact on the lean blow-out performance in a swirl-stabilized combustor. They found that the discharge was more efficient in the outer recirculation zone than close to the injector.

In academic burners dedicated to plasma-assisted combustion studies, there is most of the time no recirculation of the burnt gases. The discharge is logically located in the unburnt gases. In practical applications however, the flow dynamics are generally more complex and highly turbulent. Whether discharge effects are more favorable to combustion in the unburnt gases or in the burnt gases that recirculate and mix with unburnt gases remains an open question. 
In this study, the discharge is located in the recirculation zone downstream of the bluff-body, mainly composed of hot burnt gases. This configuration had been found to be the most favourable location in the early studies on a similar burner by Pilla et al [4].

\section{B. Bluff-body dynamics}

Low velocities in the recirculation zone downstream of the bluff-body, increase the residence time of hot combustion products, which mix with unburnt gases and thus stabilize the combustion process. Moreover, heat and radicals produced by the discharge are convected toward the shear layer where they ignite fresh gases [26].

At the operating conditions chosen for this study $\left(\dot{Q}_{a i r}=16 \mathrm{Nm}^{3} \cdot \mathrm{h}^{-1}\right.$ and $\left.\dot{Q}_{C_{4}}=1.34 \mathrm{Nm}^{3} \cdot \mathrm{h}^{-1}\right)$, without discharge the flame is confined to the recirculation zone as shown in Fig. 4 (left). This weak flame is close to extinction due to the lean equivalence ratio and high bulk velocity greater than the flame speed. In this case, the burner is near its extinction limit and a large amount of fresh gases is not burnt. Once the discharges are applied, the flame becomes fully developed, as shown in Fig. 4 (right).

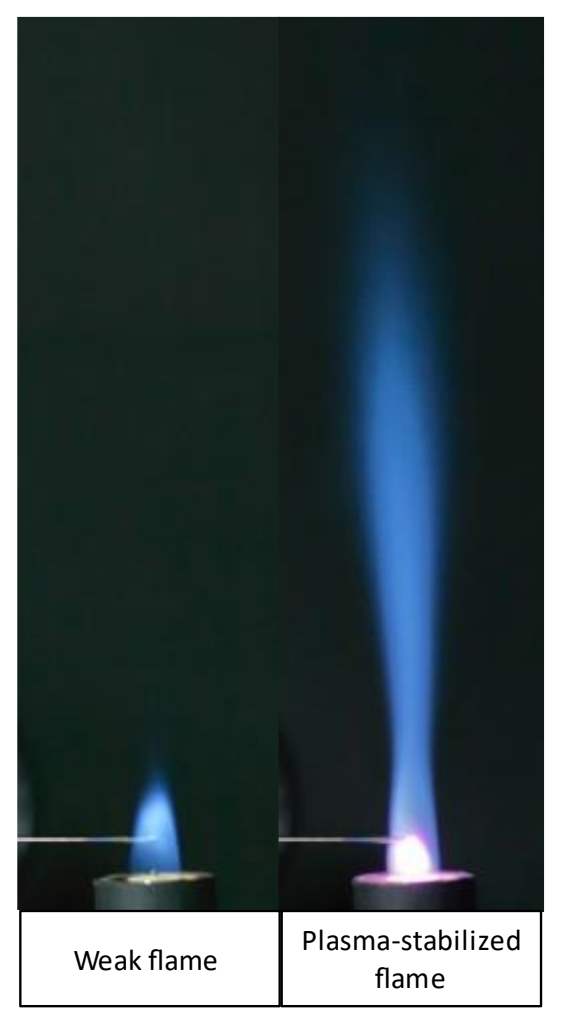

Fig. 4 Photographs without (left) and with NRP discharges applied at $20 \mathrm{kHz}$ (right) in a lean flame

NRP discharges significantly increase the temperature and produce radicals, both contribute directly to burning velocity increase [27]. The flame front can thus propagate to high-speed flow regions.

This operating point is therefore very convenient to study the most relevant effects of NRP discharges. In the following sections, the temperature increase and the production of excited nitrogen are investigated with Optical Emission Spectroscopy. 


\section{Discharge imaging}

Single-shot images of the discharge are acquired with a time step of $1 \mathrm{~ns}$ and an integration window of $2 \mathrm{~ns}$, as shown in Fig. 5. The discharge diameter is defined as the full width at half-maximum of the total emission. Time $t=0 \mathrm{~ns}$ is defined as the rising half-maximum of the total discharge emission during the high-voltage pulse.

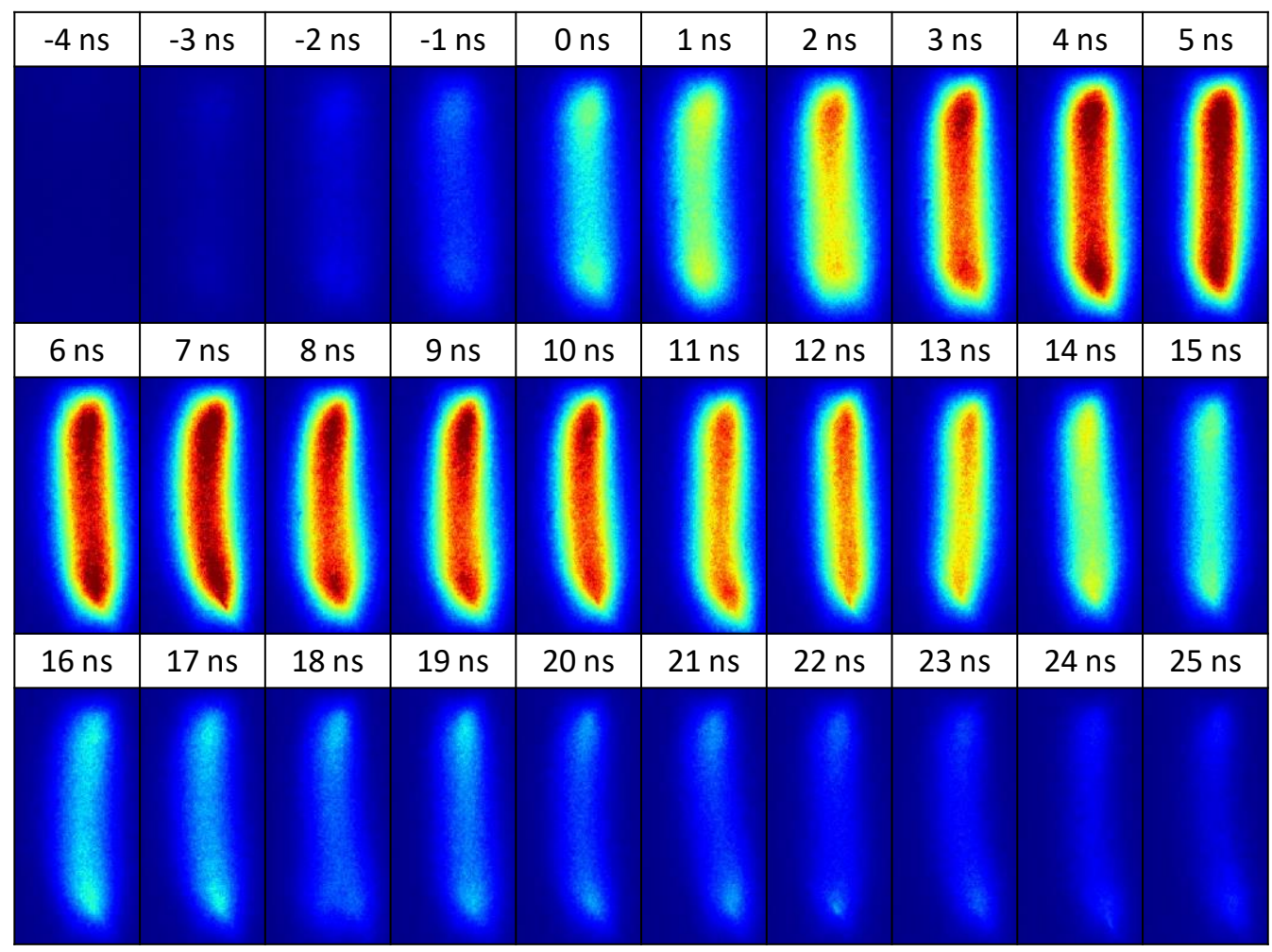

Fig. 5 Single-shot discharge images, with a 2-ns integration window and a 1-ns time step

Fig. 5 shows that the discharge is not completely homogeneous. We thus expect a spatial variation of temperature and species number density along the discharge axis. To examine this effect, the discharge is divided into three regions, namely the "anode", "middle", and "cathode" regions, shown in Fig. 6.

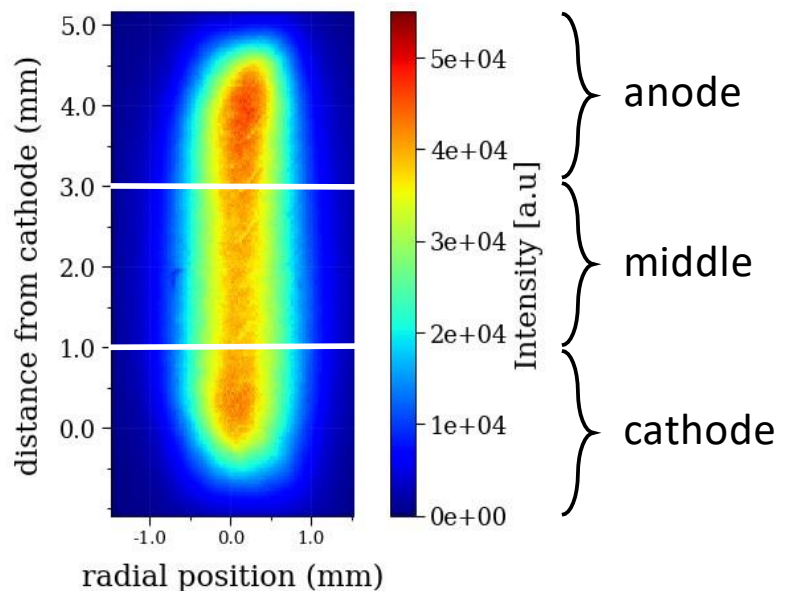

Fig. 6 Vertical partitioning of the discharge in three regions

The spatial and temporal resolution of the discharge diameter is represented in Fig. 8 and is mainly used to determine the absolute number density of $\mathrm{N}_{2}(\mathrm{C})$. 


\section{Temperatures and $\mathrm{N}_{2}(\mathrm{C})$ number density}

The emission spectrum of the $\mathrm{N}_{2}$ second positive system is studied to determine the rotational, vibrational, and absolute number density of $\mathrm{N}_{2}(\mathrm{C})$. An experimental spectrum fitted with SPECAIR [22] is shown in Fig. 7.

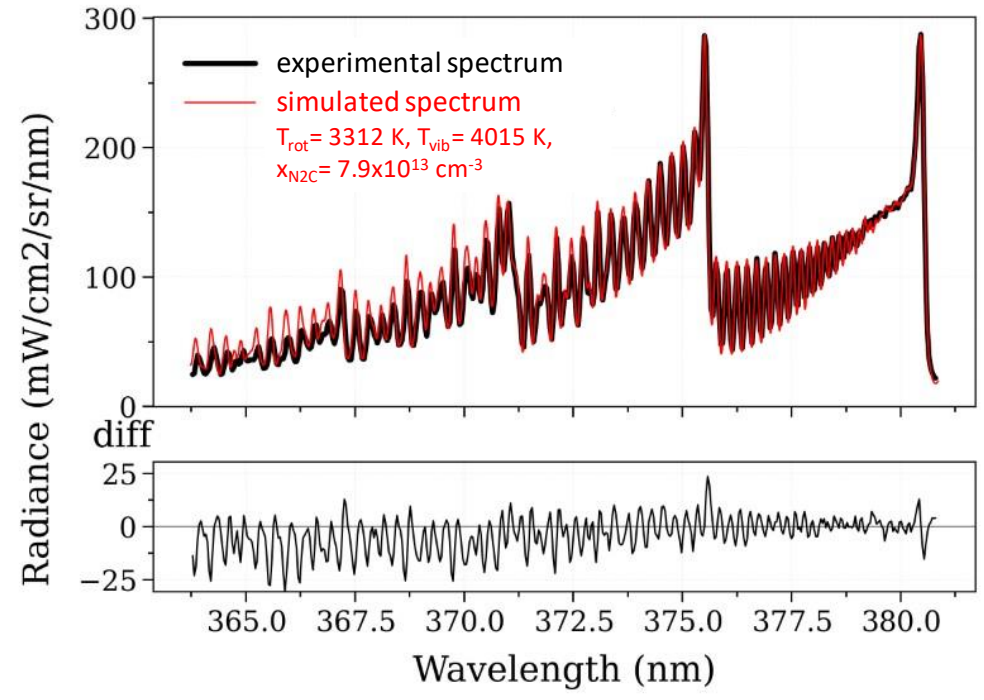

Fig. 7 Experimental calibrated spectrum and SPECAIR simulated spectrum [22]

The $\mathrm{N}_{2}(\mathrm{C})$ state is mostly populated by electron impact excitation of $\mathrm{N}_{2}(\mathrm{X})$. This reaction maps the rotational distribution of $\mathrm{N}_{2}(X)$ which is close to the gas temperature. The rotational temperature of $\mathrm{N}_{2}(C)$ is therefore within $10 \%$ of the gas temperature [17]. This 10\%-difference is further reduced by the rotational-translational relaxation (see also the discussion in [28] p. 15). Therefore, in our conditions, the gas temperature is well represented by the $\mathrm{N}_{2}(\mathrm{C})$ rotational temperature.

The vibrational temperature, shown in Fig. 8, stays around $4000 \mathrm{~K}$, which is typical for the vibrational temperature of $\mathrm{N}_{2}(\mathrm{C})$ produced by electron impact, as discussed by Rusterholtz et al. [26]. 
In steady-state pulsing, the rotational temperature at the beginning of each pulse is already above the adiabatic flame temperature of a methane-air mixture with an equivalence ratio of $0.8, \mathrm{~T}_{\text {adia }}=1992 \mathrm{~K}$. This is due to the cumulative effects of the previous pulses applied at $20 \mathrm{kHz}$.

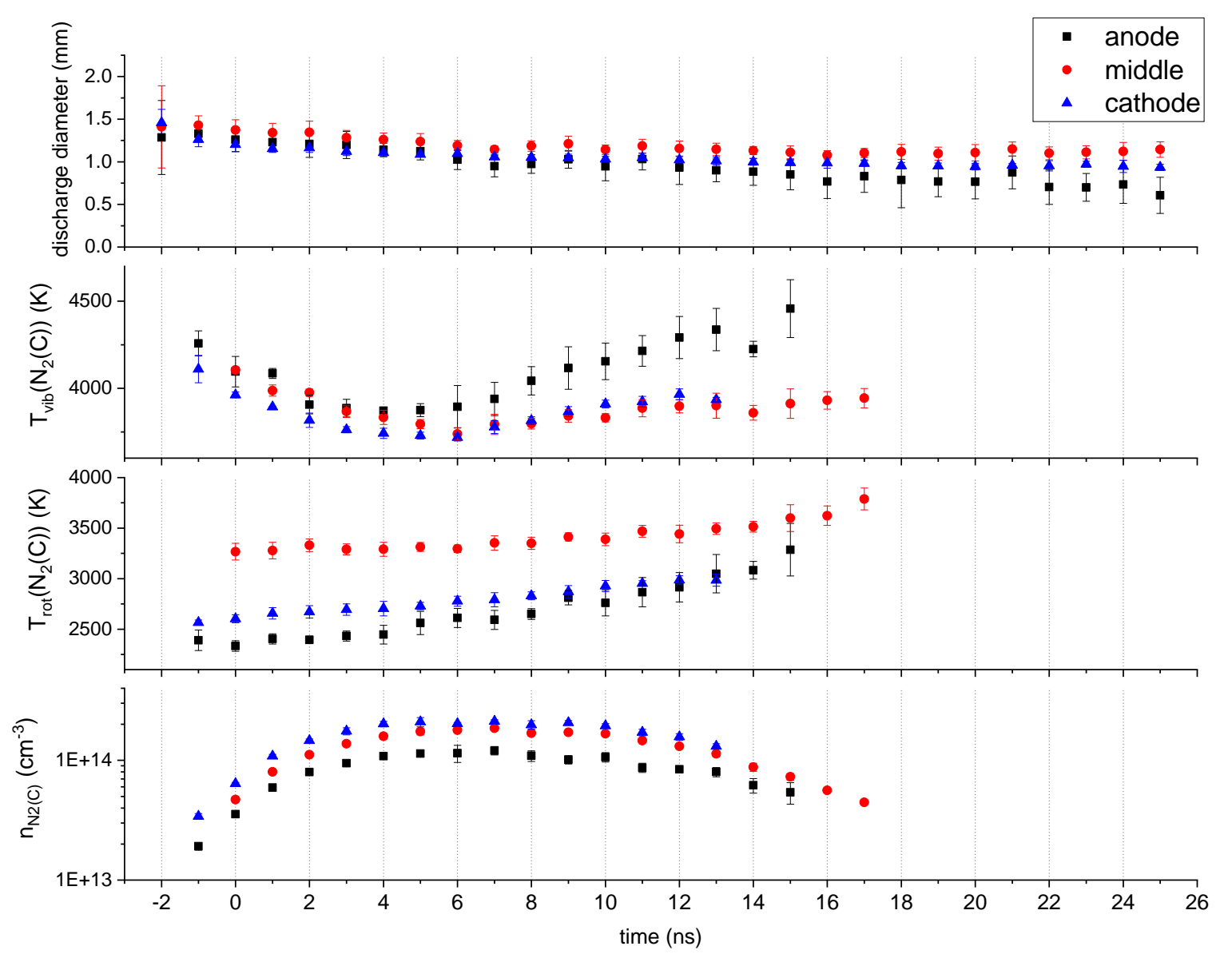

Fig. 8 Evolution of discharge diameter, rotational and vibrational temperatures, and number density of $\mathrm{N}_{2}(\mathrm{C})$

The temperature is higher in the middle of the gap than near the electrodes. This is due to hydrodynamic effects, as explained by Minesi [29].

In the middle of the gap, the temperature increases by $100 \mathrm{~K}$ from $\mathrm{t}=0 \mathrm{~ns}$ to $\mathrm{t}=8 \mathrm{~ns}$ and then by $400 \mathrm{~K}$ from $\mathrm{t}=9 \mathrm{~ns}$ to $t=17 \mathrm{~ns}$. We also observe that the $\mathrm{N}_{2}(\mathrm{C})$ number density starts to decrease after $\mathrm{t}=9 \mathrm{~ns}$. The heating is then four times more important during the quenching phase of $\mathrm{N}_{2}(\mathrm{C})$ rather than during the pulse where electron-impact reactions dominate. It indicates that similarly to NRP discharges in air [17], dissociative quenching reactions are the main contributors to gas heating.

This result is also true near the anode with a temperature increase of about $250 \mathrm{~K}$ during the electron-impact reactions followed by a temperature increase of about $500 \mathrm{~K}$ during the quenching phase.

However, near the cathode, the behavior is different. The temperature increase is higher during the electron impact reactions. This observation needs to be further investigated.

\section{Conclusion}

A lean premixed methane-air flame with a theoretical power of $13.3 \mathrm{~kW}$ is stabilized using NRP discharges with a mean electric power of $40 \mathrm{~W}$. Discharges are applied in the recirculation zone induced by the bluff-body. In this region, the gas is mainly composed of hot combustion products. This study reports spectroscopic measurements to 
quantify the effects of NRP discharges applied to a lean flame. We confirmed the existence of a fast heating mechanism due to the quenching of $\mathrm{N}_{2}$ excited states. The production of radicals by the discharge will be investigated in future work.

\section{Acknowledgments}

This work was funded by the ANR grant PASTEC ANR16-CE22-0005. The authors would like to thank Cécile Oriot, CentraleSupélec, for the flame pictures in Fig. 4, and Yannick Le Teno, CentraleSupélec, for technical support on the Mini-PAC burner.

\section{References}

[1] Y. Liu, X. Sun, V. Sethi, D. Nalianda, Y. G. Li, and L. Wang, "Review of modern low emissions combustion technologies for aero gas turbine engines,” Prog. Aerosp. Sci., vol. 94, pp. 12-45, 2017, doi: 10.1016/j.paerosci.2017.08.001.

[2] J. Thangaraja and C. Kannan, "Effect of exhaust gas recirculation on advanced diesel combustion and alternate fuels - A review High speed Direct Injection Number of Transfer Units Start of Injection," Appl. Energy, vol. 180, pp. 169-184, 2016, doi: 10.1016/j.apenergy.2016.07.096.

[3] J. Benajes, S. Molina, R. Novella, and E. Belarte, "Evaluation of massive exhaust gas recirculation and Miller cycle strategies for mixing-controlled low temperature combustion in a heavy duty diesel engine," Energy, vol. 71, pp. 355366, 2014, doi: 10.1016/j.energy.2014.04.083.

[4] G. Pilla, D. Galley, D. A. Lacoste, F. Lacas, D. Veynante, and C. O. Laux, "Stabilization of a Turbulent Premixed Flame Using a Nanosecond Repetitively Pulsed Plasma,” IEEE Trans. Plasma Sci., vol. 34, no. 6, pp. 2471-2477, 2006, doi: $10.1109 /$ TPS.2006.886081.

[5] S. Barbosa et al., "Influence of nanosecond repetitively pulsed discharges on the stability of a swirled propane/air burner representative of an aeronautical combustor," Philos. Trans. R. Soc. A Math. Phys. Eng. Sci., vol. 373, no. 2048, 2015, doi: 10.1098/rsta.2014.0335.

[6] G. T. Kim, C. S. Yoo, S. H. Chung, and J. Park, "Effects of non-thermal plasma on the lean blowout limits and CO/NOx emissions in swirl-stabilized turbulent lean-premixed flames of methane/air," Combust. Flame, vol. 212, no. x, pp. 403414, 2020, doi: 10.1016/j.combustflame.2019.11.024.

[7] R. Rajasegar, C. M. Mitsingas, E. K. Mayhew, S. Hammack, H. Do, and T. Lee, "Effects of continuous volumetric directcoupled nonequilibrium atmospheric microwave plasma discharge on swirl-stabilized premixed flames," IEEE Trans. Plasma Sci., vol. 44, no. 1, pp. 39-48, 2016, doi: 10.1109/TPS.2015.2499754.

[8] G. Vignat et al., "Improvement of lean blow out performance of spray and premixed swirled flames using nanosecond repetitively pulsed discharges," Proc. Combust. Inst., pp. 1-8, 2020, doi: 10.1016/j.proci.2020.06.136.

[9] J. K. Lefkowitz and T. Ombrello, "Reduction of flame development time in nanosecond pulsed high frequency discharge ignition of flowing mixtures," Combust. Flame, vol. 193, pp. 471-480, 2018, doi: 10.1016/j.combustflame.2018.04.009.

[10] D. A. Xu, D. A. Lacoste, and C. O. Laux, "Ignition of Quiescent Lean Propane-Air Mixtures at High Pressure by Nanosecond Repetitively Pulsed Discharges," Plasma Chem. Plasma Process., vol. 36, no. 1, pp. 309-327, 2016, doi: 10.1007/s11090-015-9680-3.

[11] D. A. Lacoste, J. P. Moeck, D. Durox, C. O. Laux, and T. Schuller, "Effect of Nanosecond Repetitively Pulsed Discharges on the Dynamics of a Swirl-Stabilized Lean Premixed Flame," J. Eng. Gas Turbines Power, vol. 135, 2013, doi: $10.1115 / 1.4024961$.

[12] J. P. Moeck, D. A. Lacoste, C. O. Laux, and C. O. Paschereit, "Control of combustion dynamics in a swirl-stabilized combustor with nanosecond repetitively pulsed discharges," 51st AIAA Aerosp. Sci. Meet. Incl. New Horizons Forum Aerosp. Expo. 2013, no. January, pp. 1-11, 2013, doi: 10.2514/6.2013-565.

[13] D. H. Lee, K. T. Kim, H. S. Kang, Y. H. Song, and J. E. Park, "Plasma-assisted combustion technology for NOx reduction in industrial burners," Environ. Sci. Technol., vol. 47, no. 19, pp. 10964-10970, 2013, doi: 10.1021/es401513t.

[14] C. H. Kruger, C. O. Laux, L. Yu, D. M. Packan, and L. Pierrot, "Nonequilibrium discharges in air and nitrogen plasmas at atmospheric pressure," Pure Appl. Chem., vol. 74, no. 3, pp. 337-347, 2002, doi: 10.1351/pac200274030337.

[15] D. Z. Pai, D. a Lacoste, and C. O. Laux, "Nanosecond repetitively pulsed discharges in air at atmospheric pressure- the spark regime,” Plasma Sources Sci. Technol., vol. 19, no. 6, p. 065015, Nov. 2010, doi: 10.1088/0963-0252/19/6/065015.

[16] D. Z. Pai, D. A. Lacoste, and C. O. Laux, "Transitions between corona, glow, and spark regimes of nanosecond repetitively pulsed discharges in air at atmospheric pressure," J. Appl. Phys., vol. 107, no. 9, 2010, doi: 10.1063/1.3309758.

[17] D. L. Rusterholtz, D. A. Lacoste, G. D. Stancu, D. Z. Pai, and C. O. Laux, "Ultrafast heating and oxygen dissociation in atmospheric pressure air by nanosecond repetitively pulsed discharges," J. Phys. D. Appl. Phys., vol. 46, no. 46, p. 464010, Nov. 2013, doi: 10.1088/0022-3727/46/46/464010.

[18] N. A. Popov, "Pulsed nanosecond discharge in air at high specific deposited energy: Fast gas heating and active particle production," Plasma Sources Sci. Technol., vol. 25, no. 4, p. 44003, 2016, doi: 10.1088/0963-0252/25/4/044003.

[19] M. Castela et al., "A 3-D DNS and experimental study of the effect of the recirculating flow pattern inside a reactive kernel produced by nanosecond plasma discharges in a methane-air mixture," Proc. Combust. Inst., vol. 36, no. 3, 2017, doi: 10.1016/j.proci.2016.06.174.

[20] Y. Bechane, N. Darabiha, V. Moureau, C. Laux, and B. Fiorina, "Large eddy simulations of turbulent flame ignition by 
nanosecond repetitively pulsed discharges," AIAA Scitech 2019 Forum, pp. 1-11, 2019, doi: 10.2514/6.2019-0742.

[21] Y. Bechane and B. Fiorina, "Numerical investigations of turbulent premixed flame ignition by a series of Nanosecond Repetitively Pulsed discharges," Proc. Combust. Inst., vol. 000, pp. 1-8, 2020, doi: 10.1016/j.proci.2020.06.258.

[22] C. O. Laux, T. G. Spence, C. H. Kruger, and R. N. Zare, "Optical diagnostics of atmospheric pressure air plasmas," Plasma Sources Sci. Technol., vol. 12, no. 2, pp. 125-138, May 2003, doi: 10.1088/0963-0252/12/2/301.

[23] G. D. Stancu, F. Kaddouri, D. A. Lacoste, and C. O. Laux, "Atmospheric pressure plasma diagnostics by OES , CRDS and TALIF," 2010, doi: 10.1088/0022-3727/43/12/124002.

[24] R. Snoeckx and M. S. Cha, "Inevitable chemical effect of balance gas in low temperature plasma assisted combustion," Combust. Flame, vol. 225, pp. 1-4, 2021, doi: 10.1016/j.combustflame.2020.10.028.

[25] W. Kim, H. Do, M. G. Mungal, and M. A. Cappelli, "Optimal discharge placement in plasma-assisted combustion of a methane jet in cross flow," Combust. Flame, vol. 153, no. 4, pp. 603-615, 2008, doi: 10.1016/j.combustflame.2007.11.015.

[26] D. A. Lacoste, D. A. Xu, J. P. Moeck, and C. O. Laux, "Dynamic response of a weakly turbulent lean-premixed flame to nanosecond repetitively pulsed discharges," vol. 34, pp. 3259-3266, 2013, doi: 10.1016/j.proci.2012.07.017.

[27] Y. Ju and W. Sun, "Plasma assisted combustion: Dynamics and chemistry," Prog. Energy Combust. Sci., vol. 48, pp. 2183, 2015, doi: 10.1016/j.pecs.2014.12.002.

[28] P. J. Bruggeman, N. Sadeghi, D. C. Schram, and V. Linss, "Gas temperature determination from rotational lines in nonequilibrium plasmas: A review,” Plasma Sources Sci. Technol., vol. 23, no. 2, 2014, doi: 10.1088/0963-0252/23/2/023001.

[29] N. Minesi, "Thermal spark formation and plasma-assisted combustion by nanosecond repetitive discharges," CentraleSupélec, Université Paris Saclay, 2020. 